\title{
Myocardial Substrate Utilization during Exercise in Humans Dual Carbon-labeled Carbohydrate Isotope Experiments
}

\author{
Edward W. Gertz, Judith A. Wisneski, William C. Stanley, and Richard A. Neese \\ Departments of Medicine and Radiology, and Cardiovascular Research Institute, University of California at San Francisco, \\ and Veterans Administration Medical Center, San Francisco, California, 94121
}

\section{Abstract}

The purpose of this study was to investigate myocardial substrate utilization during moderate intensity exercise in humans. Coronary sinus and arterial catheters were inserted in nine healthy trained male subjects (mean age, $25 \pm 6$ (SD) years). Dual carbon-labeled isotopes were infused, and substrate oxidation was quantitated by measuring myocardial production of ${ }^{14} \mathrm{CO}_{2}$. Supine cycle ergometer exercise was performed at $40 \%$ of the subject's maximal $\mathrm{O}_{2}$ uptake.

With exercise there was a significant increase in the arterial lactate level $(P<0.05)$. A highly significant positive correlation was observed between the lactate level and the isotopic lactate extraction $(r=0.93 ; P<0.001)$. The myocardial isotopic lactate uptake increased from $34.9 \pm 6.5 \mu \mathrm{mol} / \mathrm{min}$ at rest to $120.4 \pm 36.5 \mu \mathrm{mol} / \mathrm{min}$ at $5 \mathrm{~min}$ of exercise $(P<0.005)$. The ${ }^{14} \mathrm{CO}_{2}$ data demonstrated that $100.4 \pm 3.5 \%$ of the lactate extracted as determined by isotopic analysis underwent oxidative decarboxylation.

Myocardial glucose uptake also increased significantly with exercise $(P<0.04)$. The $\left[{ }^{14} \mathrm{C}\right]$ glucose data showed that only $26.0 \pm 8.5 \%$ of the glucose extracted underwent immediate oxidation at rest, and during exercise the percentage being oxidized increased to $52.6 \pm 7.3 \%(P<0.01)$.

This study demonstrates for the first time in humans an increase in myocardial oxidation of exogenous glucose and lactate during moderate intensity exercise.

\section{Introduction}

It is well recognized that free fatty acids (FFA) are the major energy source for myocardial oxidative metabolism in the resting, postabsorptive state (1-4). Animal and human studies have shown that the myocardial extractions of the various substrates used for energy are correlated with the circulating levels of these substrates (5-8). During moderate intensity exercise, elevations of circulating lactate have been well documented (9-13). Previous studies investigating myocardial metabolism have shown that the myocardial uptake of this substrate increases during exercise (14-20); these studies measured only the arterial-venous (coronary sinus) chemical lactate difference to determine myocardial uptake. Recently we have demonstrated that the myocardium releases or produces lactate as well as extracts this substrate in young healthy resting males (21). Since simultaneous myocardial lactate extraction and release are occurring, the traditional arterial-cor-

Received for publication 15 March 1988 and in revised form 25 July 1988.

The Journal of Clinical Investigation, Inc.

Volume 82, December 1988, 2017-2025 onary sinus chemical lactate difference could underestimate the actual amount of lactate being utilized for myocardial oxidative metabolism.

Studies in humans during exercise indicate that the contribution of exogenous glucose to myocardial oxidative metabolism was decreased or unchanged during exercise $(14-17,19)$. These conclusions were based on the arterial-coronary sinus chemical glucose differences at rest and during exercise. Experiments using isolated perfused hearts have demonstrated enhanced glycolysis during conditions of increased myocardial work (22-24). Using ${ }^{14} \mathrm{C}$-labeled glucose and measuring myocardial production of ${ }^{14} \mathrm{CO}_{2}$, we found in humans that only $20 \%$ of the exogenous glucose being extracted underwent immediate oxidation at rest (21). Thus, during exercise, enhanced glycolysis could occur, resulting in an increase in exogenous glucose oxidation with minimal or no change observed in the arterial-coronary sinus glucose difference.

The purpose of the present study was to investigate the myocardial metabolic fate of exogenous glucose and lactate during moderate intensity exercise in humans. Accordingly, dual carbon-labeled isotope experiments were performed using either $\mathrm{D}-\left[6-{ }^{14} \mathrm{C}\right]$ glucose and $\mathrm{L}-\left[\mathrm{U}-{ }^{13} \mathrm{C}\right]$ lactate or $\mathrm{D}-[\mathrm{U}$ $\left.{ }^{13} \mathrm{C}\right]$ glucose and $\mathrm{L}-\left[1-{ }^{14} \mathrm{C}\right]$ lactate. Myocardial production of ${ }^{14} \mathrm{CO}_{2}$ was measured to quantitate the oxidation rate of the ${ }^{14} \mathrm{C}$-labeled substrate. Subjects were exercised on a supine cycle ergometer at $\sim 40 \%$ of their maximal $\mathrm{O}_{2}$ uptake for a duration of 25 or $50 \mathrm{~min}$.

\section{Methods}

Subject selection. Young healthy physically trained male volunteers were sought and screened as previously published (21). As part of this screening process, each subject had to complete at least stage $\mathrm{V}$ of the standard protocol of Bruce and Hornsten (25) and reach 95\% of his maximal predicted heart rate (26) on the treadmill exercise test. Before the metabolic exercise protocol, all subjects returned to the laboratory to perform a second graded exercise test in the supine position on a cycle ergometer. The purpose of this latter test was to determine their maximal $\mathrm{O}_{2}$ uptake (27) and familiarize them with supine cycling and the breathing apparatus prior to the metabolic procedure. Supine cycle ergometer exercise was performed with an initial workload of $33 \mathrm{~W}$, which was increased by $33 \mathrm{~W}$ every 2 min until voluntary cessation or fatigue. Minute ventilation, $\mathrm{O}_{2}$ consumption, and $\mathrm{CO}_{2}$ output were measured continuously during this graded exercise test using a Medical Graphics System 2000 (Medical Graphics Corp., St. Paul, MN). The physical examination and both preliminary exercise tests were performed at least $3 \mathrm{~d}$ before the metabolic study.

The protocol was approved by the Committees on Human Research of the University of California and the Veterans Administration Medical Center at San Francisco, CA. The use of radioisotopes was approved by the Radiation Safety Committee of the Veterans Administration Medical Center. Each subject was informed of the nature, purpose, and possible risks of the study before written consent was obtained. 
Protocol. The subjects were instructed to maintain a regular diet; no dietary manipulations were performed. No subject participated in an exercise program or training in the 36 -h period preceding the metabolic exercise procedure. The subjects reported for the procedure at 8 a.m. after a 12-h fast. No premedication was given. A short teflon catheter was inserted percutaneously into a left antecubital vein for isotope infusion. A 7F thermodilution flow coronary sinus catheter (Webster Laboratories, Baldwin Park, CA) was inserted and a short polyethylene catheter was placed into the right brachial artery as previously published (21).

To quantitate myocardial substrate utilization, dual carbon-labeled isotopes were infused. The subjects received either D-[6- $\left.{ }^{14} \mathrm{C}\right] \mathrm{glucose}$ and $\mathrm{L}-\left[\mathrm{U}-{ }^{13} \mathrm{C}\right]$ lactate, or $\mathrm{D}-\left[\mathrm{U}-{ }^{13} \mathrm{C}\right]$ glucose and $\mathrm{L}-\left[1-{ }^{14} \mathrm{C}\right]$ lactate. $\mathrm{D}-[6-$ $\left.{ }^{14} \mathrm{C}\right]$ glucose was obtained from New England Nuclear, Boston, MA (sp act $56.1 \mathrm{mCi} / \mathrm{mmol})$. It was sterilized by microfiltration $(0.22-\mu \mathrm{m} \mathrm{bac}-$ teriologic filter [Millipore Corp., Bedford, MA]) and diluted in $0.9 \%$ $\mathrm{NaCl}$. L- $\left[\mathrm{U}-{ }^{13} \mathrm{C}\right]$ lactate ( $>99 \%$ enrichment) was obtained from Merck, Sharp \& Dohme (St. Louis, MO) as $\mathrm{L}-\left[\mathrm{U}-{ }^{13} \mathrm{C}\right]$ sodium lactate and sterilized as above. Priming doses of $16 \mu \mathrm{Ci}$ of $\left[6-{ }^{14} \mathrm{C}\right]$ glucose and $110 \mathrm{mg}$ of [U $\left.-{ }^{13} \mathrm{C}\right]$ lactate were given; this was followed by a continuous intravenous infusion of $\left[6-{ }^{14} \mathrm{C}\right] \mathrm{glucose}$ at $10 \mu \mathrm{Ci} / \mathrm{h}$ and $\left[\mathrm{U}-{ }^{13} \mathrm{C}\right]$ lactate at $130 \mathrm{mg} / \mathrm{h}$.

For the subjects receiving glucose as the stable isotope and radioisotopic lactate, $\mathrm{D}-\left[\mathrm{U}-{ }^{13} \mathrm{C}\right]$ glucose ( $>99 \%$ enrichment) was obtained from Merck, Sharpe \& Dohme. $\mathrm{L}-\left[1-{ }^{14} \mathrm{C}\right]$ lactate was obtained from New England Nuclear (sp act $55 \mathrm{mCi} / \mathrm{mmol}$ ). These were sterilized as described above for $\left[6-{ }^{14} \mathrm{C}\right]$ glucose. After priming doses of $426 \mathrm{mg}$ of [U $\left.-{ }^{13} \mathrm{C}\right]$ glucose and $10 \mu \mathrm{Ci}$ of $\left[1-{ }^{14} \mathrm{C}\right]$ lactate, a continuous intravenous infusion of $\left[\mathrm{U}-{ }^{13} \mathrm{C}\right]$ glucose at $263 \mathrm{mg} / \mathrm{h}$ and $\left[1-{ }^{14} \mathrm{C}\right]$ lactate at $12 \mu \mathrm{Ci} / \mathrm{h}$ was begun.

We have previously shown that at rest $20 \mathrm{~min}$ is required to achieve equilibration of the arterial and coronary sinus specific activity and myocardial $\mathrm{CO}_{2}$ pool when lactate is labeled with a tracer, and that $25-30 \mathrm{~min}$ is required for a glucose tracer $(21,28)$. Thus to ensure equilibration, the first control or resting blood samples were obtained at $44 \pm 5 \mathrm{~min}$ after the priming bolus and the start of the continuous isotope infusion in this study.

Prior to the first metabolic samples, the subject's feet were positioned in the cycle ergometer and measurement of respiratory gas exchange was begun using the Medical Graphics System 2000. Minute ventilation, $\mathrm{O}_{2}$ consumption $\left(\mathrm{VO}_{2}\right){ }^{1}$ and $\mathrm{CO}_{2}$ output were measured continuously during the control metabolic samples and the entire exercise period.

Arterial and coronary sinus blood samples were drawn simultaneously. Samples were obtained for chemical concentrations of glucose, lactate, and FFA, isotopic analyses $\left({ }^{14} \mathrm{C}\right.$ and $\left.{ }^{13} \mathrm{C}\right)$ of glucose and lactate, and the $\mathrm{O}_{2}$ content. Immediately after every metabolic blood sample, heart rate, arterial pressure, and coronary sinus blood flow were recorded. Coronary sinus blood flow was determined by a thermodilution technique using room temperature normal saline infused at a rate of $46 \mathrm{ml} / \mathrm{min}(29)$.

Two sets of samples were obtained at rest (5-10 min apart). Supine cycle ergometer exercise commenced immediately at a workload that corresponded most closely to $40 \%$ of the subject's maximal $\mathrm{O}_{2}$ uptake. A pedaling frequency of $60 \mathrm{rpm}$ was maintained. In three subjects after 25 min of exercise at $40 \%$ of their maximal $\mathrm{O}_{2}$ uptake, the workload was increased to that corresponding to $80 \%$ and this was continued for $15 \mathrm{~min}$. In the remaining subjects, exercise at $40 \%$ maximal $\mathrm{O}_{2}$ uptake was continued for the entire $50 \mathrm{~min}$. Samples were obtained at 5-10 min intervals during exercise. In the three subjects exercising at the high-intensity workload ( $80 \%$ maximal $\mathrm{O}_{2}$ uptake), there was an exponential increase in the circulating lactate levels. The isotopic analysis and chemical differences may not accurately reflect myocardial substrate utilization under these conditions; thus the data at the high intensity workload will not be presented.

1. Abbreviations used in this paper: $\mathrm{MVO}_{2}$, myocardial oxygen consumption; $\mathrm{VO}_{2}$, total oxygen consumption.
Chemical analysis. Weighed blood samples for analysis of lactate, glucose, specific activities, and ${ }^{13} \mathrm{C}$ enrichments were mixed immediately with a measured volume of cold $7 \%$ perchloric acid and centrifuged. The protein-free supernatant was removed and stored at $-4^{\circ} \mathrm{C}$ for future analysis. The coefficient of variation and the methodology for the chemical substrate analyses, determination of specific activities, ${ }^{14} \mathrm{CO}_{2}$ measurement, and $\left[\mathrm{U}-{ }^{13} \mathrm{C}\right]$ lactate analysis have been published previously for our laboratory $(21,28)$.

$\left[\mathrm{U}-{ }^{13} \mathrm{C}\right.$ ]glucose content was determined using a modification of the method developed by Bier et al. (30) for 6,6-dideuteroglucose. Glucose was isolated from the protein-free supernatant by ion exchange chromatography, lyophilized, and converted to a butane-boronic-acetate derivative (31). This derivative was analyzed by gas chromatography/ mass spectrometry as described by Bier et al. (30) measuring the masses at $297\left(\mathrm{M}-\mathrm{C}_{4} \mathrm{H}_{9}\right)^{+}$corresponding to unlabeled glucose and at 303 corresponding to $\left[\mathrm{U}-{ }^{13} \mathrm{C}\right]$ labeled glucose. The enrichments were compared to a standard curve prepared by diluting $99 \%$ enriched $\left[\mathrm{U}-{ }^{13} \mathrm{C}\right]-$ glucose with unlabeled glucose.

$\mathrm{O}_{2}$ content was determined manometrically by the technique of Van Slyke and Neill (32). All isotopic and chemical analyses were performed in duplicate.

Calculations. The chemical extraction $(\mu \mathrm{mol} / \mathrm{ml})$ for a given substrate was calculated as [A] - [CS], where [A] is the arterial concentration and [CS] is the coronary sinus concentration. The chemical substrate uptake $(\mu \mathrm{mol} / \mathrm{min})$ was calculated from the chemical extraction and the coronary sinus (CS) blood flow as ([A] $-[\mathrm{CS}]) \times$ CS flow.

The isotopic lactate extraction ratio $(\%)$ for $\left[\mathrm{U}_{-}{ }^{13} \mathrm{C}\right]$ lactate was calculated as $\left([\mathrm{A}] \times \%{ }^{13} \mathrm{C}_{3}\right.$ in artery $-[\mathrm{CS}] \times \%{ }^{13} \mathrm{C}_{3}$ in $\left.\mathrm{CS}\right) /\left([\mathrm{A}] \times \%{ }^{13} \mathrm{C}_{3}\right.$ in artery) $\times 100$, where $\%{ }^{13} \mathrm{C}_{3}=\left(\left[{ }^{13} \mathrm{C}_{3}\right]\right.$ lactate $) /($ chemical lactate $)$ $\times 100$.

The isotopic lactate extraction ratio $(\%)$ for $\left[{ }^{14} \mathrm{C}\right]$ lactate was calculated as $([\mathrm{A}] \times$ sp act lactate in artery $-[\mathrm{CS}] \times$ sp act lactate in CS $) /([\mathrm{A}]$ $X$ sp act lactate in artery) $\times 100$.

The myocardial isotopic lactate extraction $(\mu \mathrm{mol} / \mathrm{ml})$ was determined from either the $\left[\mathrm{U}-{ }^{13} \mathrm{C}\right]$ lactate or $\left[{ }^{14} \mathrm{C}\right]$ lactate extraction ratio as [A] $\times$ isotopic lactate extraction ratio $(\%) / 100$. The isotopic lactate uptake $(\mu \mathrm{mol} / \mathrm{min})$ was obtained from the isotopic lactate extraction $\times$ CS flow. Myocardial lactate release $(\mu \mathrm{mol} / \mathrm{ml})$ represents the difference between the isotopic lactate and the chemical lactate extraction (28).

The oxidation of exogenous glucose or lactate labeled with ${ }^{14} \mathrm{C}$ $(\mu \mathrm{mol} / \mathrm{ml})$ was calculated as $\left((\mathrm{CS}-\mathrm{A}){ }^{14} \mathrm{CO}_{2} \mathrm{dpm} / \mathrm{ml}\right) /($ arterial specific activity of substrate).

Since other substrates are labeled secondarily when tracers are infused, the ( $\mathrm{CS}-\mathrm{A}){ }^{14} \mathrm{CO}_{2}$ was corrected for the possible oxidation of the secondarily labeled substrates as previously published $(21,28)$.

Using dual-carbon labeled isotopes of glucose and lactate and measuring the arterial and coronary sinus enrichments of the stable isotopes and the specific activities of glucose and lactate allow quantitation of the conversion of exogenous glucose to lactate being produced by the myocardium (21).

Myocardial oxygen consumption ( $\mathrm{ml} / \mathrm{min}$ ) was calculated from the arterial-coronary sinus difference in the oxygen content $(\mathrm{ml} / 100 \mathrm{ml})$ and the CS flow as (A - CS) $\mathrm{O}_{2} \times \mathrm{CS}$ flow.

Statistical analysis. To compare the arterial substrate levels, myocardial substrate extractions and uptakes at rest with the various time periods during exercise, the Wilcoxon matched-pairs signed rank test (33) with the Bonferroni correction (34) was used. Linear regression analyses were performed to correlate the arterial substrate levels with the myocardial extraction (35). The data are presented as means \pm SE unless otherwise specified.

\section{Results}

The study group consisted of nine healthy trained male subjects. Their ages, weights, maximal $\mathrm{O}_{2}$ uptake, and type of training are given in Table $\mathrm{I}$. The mean maximal $\mathrm{O}_{2}$ uptake in 
Table I. Physical Description and Exercise Performance of Subjects

\begin{tabular}{|c|c|c|c|c|c|c|}
\hline \multirow[b]{2}{*}{ Subject* } & \multirow[b]{2}{*}{ Age } & \multirow[b]{2}{*}{ Weight } & \multirow[b]{2}{*}{$\mathrm{VO}_{2} \max$} & \multirow[b]{2}{*}{ Training } & \multicolumn{2}{|c|}{ Exercise metabolic study } \\
\hline & & & & & $\mathrm{vO}_{2} \max$ & Duration \\
\hline & $y r$ & $k g$ & $\mathrm{ml} / \mathrm{kg} \cdot \min$ & & $\%$ & $\min$ \\
\hline 1 & 26 & 84.0 & 48.7 & Competitive rower & 42 & 25 \\
\hline 2 & 30 & 72.7 & 53.2 & Competitive triathlete & 53 & 25 \\
\hline 3 & 38 & 82.7 & 50.7 & Recreational runner & 48 & 25 \\
\hline 4 & 20 & 93.0 & 50.8 & Competitive rower & 46 & 50 \\
\hline 5 & 32 & 76.6 & 66.8 & Competitive triathlete & 39 & 50 \\
\hline 6 & 19 & 82.1 & 54.8 & Recreational cyclist & 39 & 50 \\
\hline 7 & 20 & 78.1 & 47.1 & Recreational runner & 40 & 50 \\
\hline 8 & 21 & 58.5 & 69.5 & Competitive cyclist & 40 & 50 \\
\hline 9 & 20 & 65.9 & 56.7 & Competitive cyclist & 45 & 50 \\
\hline Mean \pm SD & $25 \pm 6$ & $77.1 \pm 9.7$ & $55.4 \pm 7.4$ & & $44 \pm 4$ & \\
\hline
\end{tabular}

Data represent mean $\pm \mathrm{SD} . \mathrm{VO}_{2} \max$, maximal $\mathrm{O}_{2}$ consumption. $\quad{ }^{*}\left[6-{ }^{14} \mathrm{C}\right]$ glucose and $\left[\mathrm{U}-{ }^{13} \mathrm{C}\right]$ lactate were infused in subjects $1-6 .\left[\mathrm{U}-{ }^{13} \mathrm{C}\right] \mathrm{glu}-$ cose and $\left[1-{ }^{14} \mathrm{C}\right]$ lactate were infused in subjects 7,8 , and 9 .

these subjects was $55.4 \pm 7.4(\mathrm{SD}) \mathrm{ml} / \mathrm{kg} \cdot \mathrm{min}$, which is high for supine exercise and is an indication of the subjects' level of training $(36,37)$. An attempt was made to exercise each subject at $40 \%$ of his maximal $\mathrm{O}_{2}$ uptake during the exercise metabolic protocol. The percentage of maximal $\mathrm{O}_{2}$ uptake achieved for each individual is listed in Table I; for the group, $44 \pm 4 \%$ (SD) of their maximal $\mathrm{O}_{2}$ uptake was achieved which represented a workload of $102 \pm 15 \cdot \mathrm{W}$ (SD).

Heart rate, arterial pressure, coronary flow, and myocardial oxygen consumption $\left(\mathrm{MVO}_{2}\right)$. The heart rate, mean arterial pressure, coronary blood flow, and total body $\mathrm{O}_{2}$ uptake are given in Table II for the control period and the various times during exercise at $40 \%$ maximal $\mathrm{O}_{2}$ uptake. A significant increase in the arterial-coronary sinus $\mathrm{O}_{2}$ difference as well as a significant increase in $\mathrm{MVO}_{2}$ were observed during exercise $(P<0.04)$ (Table III).

Circulating substrates. The arterial lactate, glucose, and FFA levels are shown over time with exercise at $40 \%$ maximal $\mathrm{O}_{2}$ uptake in Fig. 1. The mean control value for arterial lactate was $0.64 \pm 0.03 \mu \mathrm{mol} / \mathrm{ml}$. In seven of the nine subjects there

Table II. Hemodynamics and Coronary Blood Flow during Exercise

\begin{tabular}{|c|c|c|c|c|c|}
\hline & \multirow[b]{2}{*}{ Rest } & \multicolumn{4}{|c|}{ Minutes during exercise at $40 \% \mathrm{VO}_{2} \max$} \\
\hline & & $5-10$ & $15-20$ & $25-30$ & 50 \\
\hline Heart rate $(b p m)$ & $63 \pm 2$ & $\underset{8}{117 \pm 2}$ & $122 \pm 3$ & $124 \pm 3$ & $\underset{ \pm}{126 \pm 3}$ \\
\hline $\begin{array}{l}\text { Mean arterial } \\
\text { pressure }(m m H g)\end{array}$ & $101 \pm 3$ & $\stackrel{108 \pm 4}{*}$ & $\begin{array}{c}104 \pm 5 \\
\text { NS }\end{array}$ & $\begin{array}{c}104 \pm 4 \\
\text { NS }\end{array}$ & $\begin{array}{c}98 \pm 3 \\
\text { NS }\end{array}$ \\
\hline $\begin{array}{l}\text { Coronary blood flow } \\
(\mathrm{ml} / \mathrm{min})\end{array}$ & $114 \pm 10$ & $222 \pm 15$ & $235 \pm 23$ & $\underset{8}{238 \pm 21}$ & $211 \pm 19$ \\
\hline $\begin{array}{l}\mathrm{VO}_{2}\left(m l \times k g^{-1}\right. \\
\left.\times \min ^{-1}\right)\end{array}$ & $4.6 \pm 0.3$ & $24.5 \pm 0.8$ & $\underset{8}{24.8 \pm 0.9}$ & $25.0 \pm 0.8$ & $\begin{array}{c}25.5 \pm 0.9 \\
\ddagger\end{array}$ \\
\hline
\end{tabular}

Data represent mean $\pm \mathrm{SE}$.

${ }^{*} P<0.05$ vs. control; ${ }^{\ddagger} P<0.01$ vs. control; ${ }^{\S} P<0.005$ vs. control. was an early rise and peak in arterial lactate; at $5 \mathrm{~min}$ of exercise circulating lactate was $219 \pm 27 \%$ of the control value in these subjects $(P<0.01)$. At $10 \mathrm{~min}$ of exercise the lactate level was decreasing and the level plateaued until 20-25 min of exercise; at that point the lactate level was $176 \pm 14 \%$ of control (upper graph, Fig. 1). In the remaining two subjects, the arterial lactate fell with exercise. The levels represented in Fig. 1 are the mean $\pm \mathrm{SE}$ for all nine subjects.

The mean control values for arterial glucose and FFA were $5.24 \pm 0.07$ and $0.68 \pm 0.07 \mu \mathrm{mol} / \mathrm{ml}$, respectively. There were no significant changes in the circulating glucose or FFA levels during the 50 min of exercise in this study (Fig. 1).

Myocardial lactate utilization. If an organ is simultaneously extracting and releasing (producing) a substrate, the arterial-venous chemical difference will be less than the isotopic extraction. In all subjects at rest and during moderate exercise, the arterial-coronary sinus chemical lactate difference was less than the isotopic lactate extraction. At rest the chemical lactate difference was $40.2 \pm 4.4 \%$ lower than the isotopic lactate extraction; this difference varied from $25.1 \%$ to $62.4 \%$ in these nine subjects. This finding demonstrates that the myocardium is releasing lactate in healthy trained subjects. It also shows that the traditional arterial-coronary sinus lactate difference underestimates the actual amount of lactate extracted by the myocardium. In this study the chemical lactate uptake underestimated the actual or isotopic lactate uptake by $40.2 \pm 4.4 \%$ at rest and by $21.6 \pm 1.4 \%$ during exercise.

The isotopic and chemical extractions for lactate during the control period and the various time points of exercise are summarized in Table III. With coronary sinus flow measurements, the myocardial uptake can be calculated and expressed in micromoles per minute. The myocardial isotopic lactate and chemical uptakes are compared over the time course of exercise in Fig. 2. If the myocardial lactate uptake during the various time periods of exercise is compared with the arterial lactate level (Fig. 1 and Table III), one finds that the lactate uptake is very dependent on the circulating level of this substrate. Fig. 3 shows the correlation between the isotopic lactate extraction and the arterial lactate level for each data point in these nine subjects at rest and during moderate exercise. A 


\begin{tabular}{|c|c|c|c|c|c|}
\hline & \multirow[b]{2}{*}{ Rest } & \multicolumn{4}{|c|}{ Minutes during exercise at $40 \% \mathrm{VO}_{2} \max$} \\
\hline & & $5-10$ & $15-20$ & $25-30$ & 50 \\
\hline Arterial lactate $(\mu \mathrm{mol} / \mathrm{ml})$ & $0.64 \pm 0.03$ & $\underset{\S}{1.07 \pm 0.22}$ & $\underset{\S}{0.96 \pm 0.16}$ & $\underset{\S}{0.94 \pm 0.13}$ & $\begin{array}{c}0.66 \pm 0.07 \\
\mathrm{NS}\end{array}$ \\
\hline A-CS chemical lactate $(\mu \mathrm{mol} / \mathrm{ml})$ & $0.18 \pm 0.03$ & $\underset{\S}{0.42 \pm 0.09}$ & $\begin{array}{c}0.35 \pm 0.06 \\
*\end{array}$ & $\begin{array}{c}0.32 \pm 0.04 \\
\text { NS }\end{array}$ & $\begin{array}{c}0.21 \pm 0.03 \\
\mathrm{NS}\end{array}$ \\
\hline Chemical lactate uptake $(\mu \mathrm{mol} / \mathrm{min})$ & $22.7 \pm 5.1$ & $\underset{\|}{91.5 \pm 26.2}$ & $\underset{\|}{85.3 \pm 19.9}$ & $\underset{\S}{81.3 \pm 16.0}$ & $\begin{array}{c}44.3 \pm 7.1 \\
\text { NS }\end{array}$ \\
\hline Isotopic lactate extracted $(\mu \mathrm{mol} / \mathrm{ml})$ & $0.29 \pm 0.04$ & $\begin{array}{c}0.51 \pm 0.11 \\
\ddagger\end{array}$ & $\begin{array}{c}0.44 \pm 0.07 \\
*\end{array}$ & $\begin{array}{c}0.39 \pm 0.05 \\
\text { NS }\end{array}$ & $\begin{array}{c}0.30 \pm 0.02 \\
\mathrm{NS}\end{array}$ \\
\hline Isotopic lactate uptake $(\mu \mathrm{mol} / \mathrm{min})$ & $34.9 \pm 6.5$ & $\underset{\|}{112.6 \pm 32.4}$ & $\underset{\|}{106.0 \pm 23.8}$ & $\underset{\|}{97.5 \pm 17.4}$ & $\begin{array}{c}63.0 \pm 7.8 \\
\text { NS }\end{array}$ \\
\hline Arterial glucose $(\mu \mathrm{mol} / \mathrm{ml})$ & $5.24 \pm 0.07$ & $\begin{array}{c}5.26 \pm 0.09 \\
\text { NS }\end{array}$ & $\begin{array}{l}5.30 \pm 0.06 \\
\mathrm{NS}\end{array}$ & $\begin{array}{c}5.34 \pm 0.06 \\
\text { NS }\end{array}$ & $\begin{array}{c}5.28 \pm 0.11 \\
\text { NS }\end{array}$ \\
\hline A-CS glucose $(\mu \mathrm{mol} / \mathrm{ml})$ & $0.23 \pm 0.04$ & $\begin{array}{l}0.19 \pm 0.04 \\
\text { NS }\end{array}$ & $\begin{array}{c}0.24 \pm 0.04 \\
\text { NS }\end{array}$ & $\begin{array}{c}0.23 \pm 0.04 \\
\text { NS }\end{array}$ & $\begin{array}{c}0.24 \pm 0.05 \\
\text { NS }\end{array}$ \\
\hline Glucose uptake ( $\mu \mathrm{mol} / \mathrm{min})$ & $28.1 \pm 6.1$ & $\underset{\|}{47.0 \pm 9.3}$ & $\underset{\|}{58.6 \pm 13.2}$ & $\underset{\|}{56.3 \pm 13.1}$ & $\underset{8}{51.4 \pm 10.3}$ \\
\hline Exogenous glucose oxidation $(\mu \mathrm{mol} / \mathrm{ml})^{\uparrow}$ & $0.08 \pm 0.03$ & $\underset{\S}{0.11 \pm 0.04}$ & $\underset{\S}{0.13 \pm 0.04}$ & $\underset{\S}{0.13 \pm 0.04}$ & $0.10 \pm 0.02$ \\
\hline Rate of exogenous glucose oxidation $(\mu \mathrm{mol} / \mathrm{min})^{\prime}$ & $10.6 \pm 5.1$ & $\underset{\S}{27.7 \pm 10.4}$ & $\underset{\S}{37.2 \pm 15.3}$ & $\underset{\S}{36.6 \pm 13.0}$ & $22.0 \pm 3.2$ \\
\hline Arterial FFA $(\mu \mathrm{mol} / \mathrm{ml})$ & $0.68 \pm 0.07$ & $\begin{array}{l}0.64 \pm 0.04 \\
\text { NS }\end{array}$ & $\begin{array}{l}0.70 \pm 0.06 \\
\quad \text { NS }\end{array}$ & $\begin{array}{l}0.75 \pm 0.05 \\
\quad \text { NS }\end{array}$ & $\begin{array}{l}0.77 \pm 0.05 \\
\text { NS }\end{array}$ \\
\hline A-CS FFA $(\mu \mathrm{mol} / \mathrm{ml})$ & $0.18 \pm 0.02$ & $\begin{array}{l}0.14 \pm 0.01 \\
\quad \neq\end{array}$ & $\begin{array}{l}0.15 \pm 0.02 \\
\quad \text { NS }\end{array}$ & $\begin{array}{l}0.16 \pm 0.02 \\
\quad \text { NS }\end{array}$ & $\begin{array}{l}0.20 \pm 0.01 \\
\text { NS }\end{array}$ \\
\hline FFA uptake $(\mu \mathrm{mol} / \mathrm{min})$ & $20.1 \pm 1.8$ & $\underset{\|}{31.8 \pm 4.1}$ & $\underset{\|}{34.1 \pm 3.5}$ & $\begin{array}{l}37.7 \pm 4.9 \\
\|\end{array}$ & $\underset{8}{43.2 \pm 6.2}$ \\
\hline $\mathrm{A}-\mathrm{CS} \mathrm{O}_{2}(\mathrm{ml} / 100 \mathrm{ml})$ & $12.3 \pm 0.4$ & $\begin{array}{c}13.6 \pm 0.4 \\
\ddagger\end{array}$ & $\begin{array}{l}13.9 \pm 0.3 \\
\neq\end{array}$ & $\begin{array}{c}14.1 \pm 0.3 \\
\ddagger\end{array}$ & $\begin{array}{c}14.3 \pm 0.7 \\
\ddagger\end{array}$ \\
\hline $\mathrm{MVO}_{2}(\mathrm{ml} / \mathrm{min})$ & $14.0 \pm 1.5$ & $\underset{11}{29.5 \pm 2.1}$ & $\underset{\|}{31.9 \pm 3.8}$ & $\underset{\|}{31.6 \pm 3.0}$ & $\underset{8}{31.7 \pm 3.4}$ \\
\hline
\end{tabular}

Data represent mean \pm SE. Abbreviations: A, arterial; $\mathrm{CS}$, coronary sinus; $\mathrm{VO}_{2}$ max, maximal oxygen consumption. $\quad * P<0.05$ vs. control; ${ }^{\ddagger} P<0.025$ vs. control; ${ }^{8} P<0.01$ vs. control; " $P<0.005$ vs. control. "Exogenous glucose oxidation only calculated in the six subjects receiving $\left[6-{ }^{14} \mathrm{C}\right]$ glucose.

highly significant positive correlation exists between the myocardial isotopic lactate extraction and the arterial level of this substrate $(r=0.93, P<0.001)$.

Three subjects received $\left[\mathrm{U}-{ }^{13} \mathrm{C}\right]$ glucose and $\left[1-{ }^{14} \mathrm{C}\right]$ lactate as tracers. Lactate was labeled with ${ }^{14} \mathrm{C}$ in the first carbon position; this carbon is released as $\mathrm{CO}_{2}$ when pyruvate is decarboxylated to form acetyl-coenzyme A. Measuring the myocardial production of ${ }^{14} \mathrm{CO}_{2}$ in these subjects allows quantitation of the amount of lactate undergoing oxidative decarboxylation in the myocardium. Fig. 4 compares the amount of lactate undergoing oxidative decarboxylation with the chemical lactate extraction (upper graph) and isotopic lactate extraction (lower graph). The dashed lines represent the lines of identity, i.e., the data points would fall on this line if the lactate extracted was equal to the amount oxidized. The lower graph shows that $100.4 \pm 3.5 \%$ of the lactate extracted as measured by the isotopic analysis underwent oxidative decarboxylation. Similar calculations for the chemical lactate extraction implies that $139.4 \pm 4.6 \%$ of the lactate extracted was oxidized. Thus, the ${ }^{14} \mathrm{CO}_{2}$ measurement indicates that the chemical lactate uptake underestimates myocardial lactate utilization and that myocardial lactate utilization is very closely correlated with the isotope lactate uptake.

Fig. 5 compares the isotopic lactate extraction, the amount of lactate undergoing oxidative decarboxylation, the chemical lactate extraction (lower graph) and the arterial lactate (upper graph) in one of the three subjects receiving $\left[1-{ }^{14} \mathrm{C}\right]$ lactate. This subject (Table I, subject 8 ) is highly trained and is one of two subjects whose circulating lactate decreased with moderate intensity exercise. In the six data points shown in Fig. 5, the ratio of lactate undergoing oxidative decarboxylation to the isotopic uptake was $0.96 \pm 0.05$ compared with $1.56 \pm 0.09$ for the ratio of lactate utilization to the chemical uptake.

Myocardial lactate release. As stated previously, myocardial release or production of lactate accounts for the difference between the isotope and chemical extraction. At rest, myocardial lactate release was $0.10 \pm 0.01 \mu \mathrm{mol} / \mathrm{ml}$ and this value fell during exercise to $0.09 \pm 0.02$ at $15-20 \mathrm{~min}$ and $0.07 \pm 0.01$ $\mu \mathrm{mol} / \mathrm{ml}$ at $25-30 \mathrm{~min}$. The rate of lactate released was $12.2 \pm 1.6 \mu \mathrm{mol} / \mathrm{min}$ at rest and increased slightly to $16.2 \pm 2.4$ 

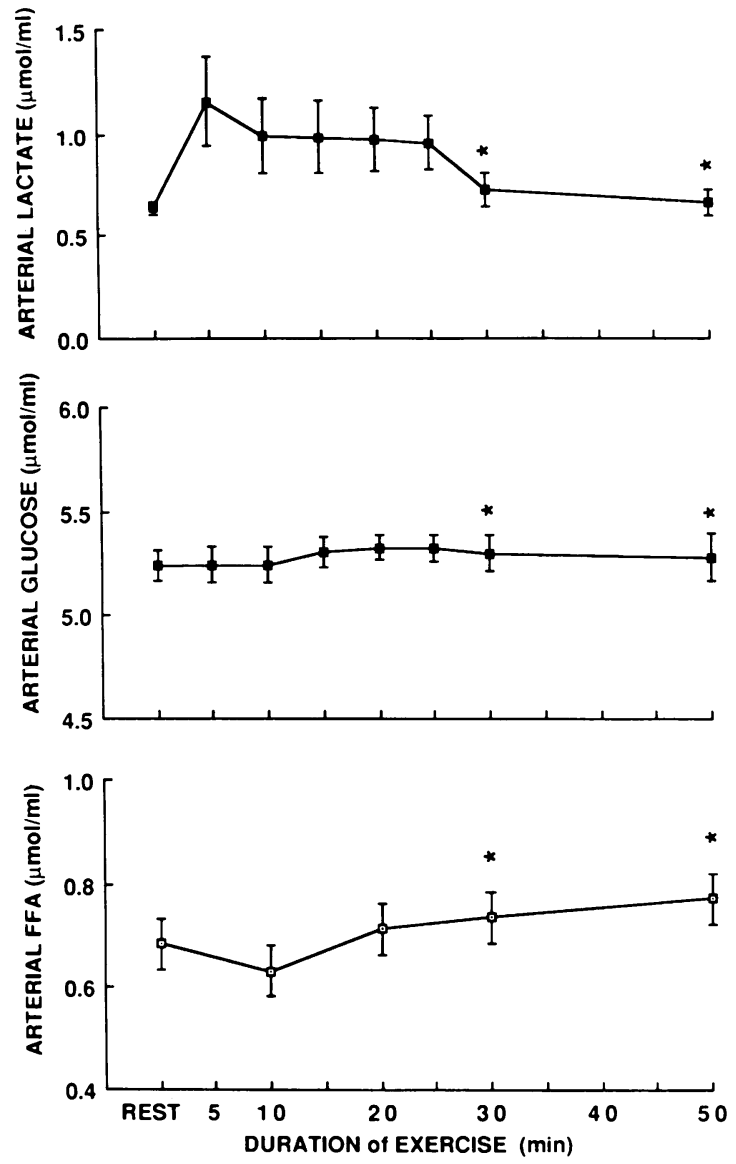

Figure 1. The arterial lactate (upper graph), glucose (middle graph), and FFA (lower graph) levels $(\mu \mathrm{mol} / \mathrm{ml})$ are presented for the preexercise control period (rest) and during the $50 \mathrm{~min}$ of exercise at $40 \%$ of maximal $\mathrm{O}_{2}$ uptake. The data are presented as mean $\pm \mathrm{SE}$ of the nine subjects. *Data only on six subjects; the arterial levels on the three subjects exercising at $79 \%$ of maximal $\mathrm{O}_{2}$ uptake were not included. There was a significant increase in arterial lactate level for the initial $25 \mathrm{~min}$ of exercise $(P<0.05)$. In the six subjects who continued exercising for $50 \mathrm{~min}$, there were no significant changes in their lactate levels compared with control at the 30- and 50-min sampling periods. The two subjects whose lactate level fell during exercise were in the latter group. No significant changes occurred in the glucose or FFA levels during exercise.

and $16.1 \pm 3.8 \mu \mathrm{mol} / \mathrm{min}$, respectively, during exercise; however these changes were not statistically significant.

Glucose utilization. Table III gives the values for myocardial glucose extraction, uptake, and exogenous glucose oxidation. There were no significant changes in the arterial-coronary sinus glucose differences $(\mu \mathrm{mol} / \mathrm{ml})$ during exercise compared with control. However if coronary sinus blood flow is taken into account, an increase in myocardial glucose uptake was observed in all nine subjects during exercise $(P<0.04)$. At 5-10 $\mathrm{min}$ and at $25-30 \mathrm{~min}$ of exercise, myocardial glucose uptake increased to $192.9 \pm 31.5 \%$ and $236.7 \pm 48.6 \%$ of the control value, respectively (Table III).

$\left[6-{ }^{14} \mathrm{C}\right]$ glucose was infused in six of the subjects. The carbon in the sixth position on glucose is released as $\mathrm{CO}_{2}$ in the citric acid cycle. By measuring the myocardial production of ${ }^{14} \mathrm{CO}_{2}$, the amount of exogenous glucose being oxidized by the myocardium can be quantitated. A significant increase in

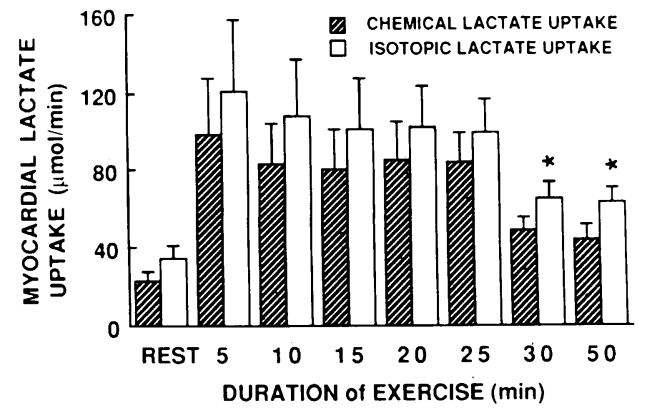

Figure 2. Comparison of the chemical and isotopic lactate uptakes by the myocardium at rest and during exercise at $40 \%$ maximal $\mathrm{O}_{2}$ uptake. Histograms represent mean \pm SE of the uptakes $(\mu \mathrm{mol} / \mathrm{ml}$ $X$ coronary sinus flow) in all nine subjects, (* except at 30 and 50 min of exercise where the mean $\pm \mathrm{SE}$ of the six subjects continuing exercise at the moderate-intensity workload are presented). Statistical analyses showed significant increases for both chemical and isotopic lactate uptakes in the nine subjects during exercise for the initial 25 minutes $(P<0.05$ and $P<0.025$, respectively). Comparison of control with the results at 30 and 50 min of exercise in six subjects showed no significant changes. The two highly trained subjects with a fall in circulating lactate during exercise were among the six subjects exercising to $50 \mathrm{~min}$, and they also had a decrease in myocardial lactate uptake in the 30 - and 50 -min periods.

myocardial exogenous glucose oxidation was observed during exercise $(P<0.03)$. Fig. 6 compares the myocardial glucose uptake and the rate of exogenous glucose oxidation in the six subjects receiving $\left[6-{ }^{14} \mathrm{C}\right]$ glucose. The percentage of the glucose extracted undergoing rapid oxidation increased significantly with exercise; the percentage at rest was $26.0 \pm 8.5 \%$ and this increased to $52.6 \pm 7.3 \%$ with exercise $(P<0.01)$.

Despite the significant increase in myocardial glucose uptake and the increase in exogenous glucose oxidation documented with the ${ }^{14} \mathrm{CO}_{2}$ data, there were no significant changes in the circulating glucose levels during exercise (Fig. 1, Table III). Regression analysis showed there was not a significant correlation between the arterial glucose level and myocardial glucose extraction $(r=0.02)$.

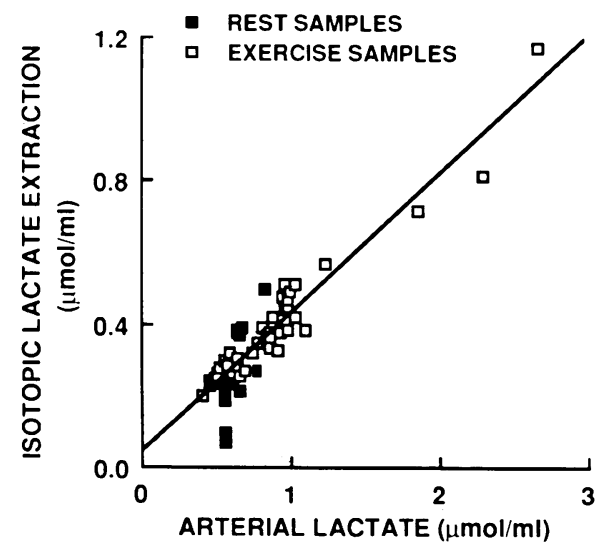

Figure 3. Correlation between the arterial lactate level and the myocardial isotopic lactate extraction in the nine subjects at rest ( $(\boldsymbol{)})$ and during exercise ( $\square$ ). The isotopic lactate extraction was determined by ${ }^{14} \mathrm{C}$ or ${ }^{13} \mathrm{C}$ analysis. Linear regression analysis gives $r=0.93$ ( $P$ $<0.001$ ) with $n=57, y=0.38 x+0.05$; standard error of the estimate $y$ on $x=0.06 \mu \mathrm{mol} / \mathrm{ml}$. 

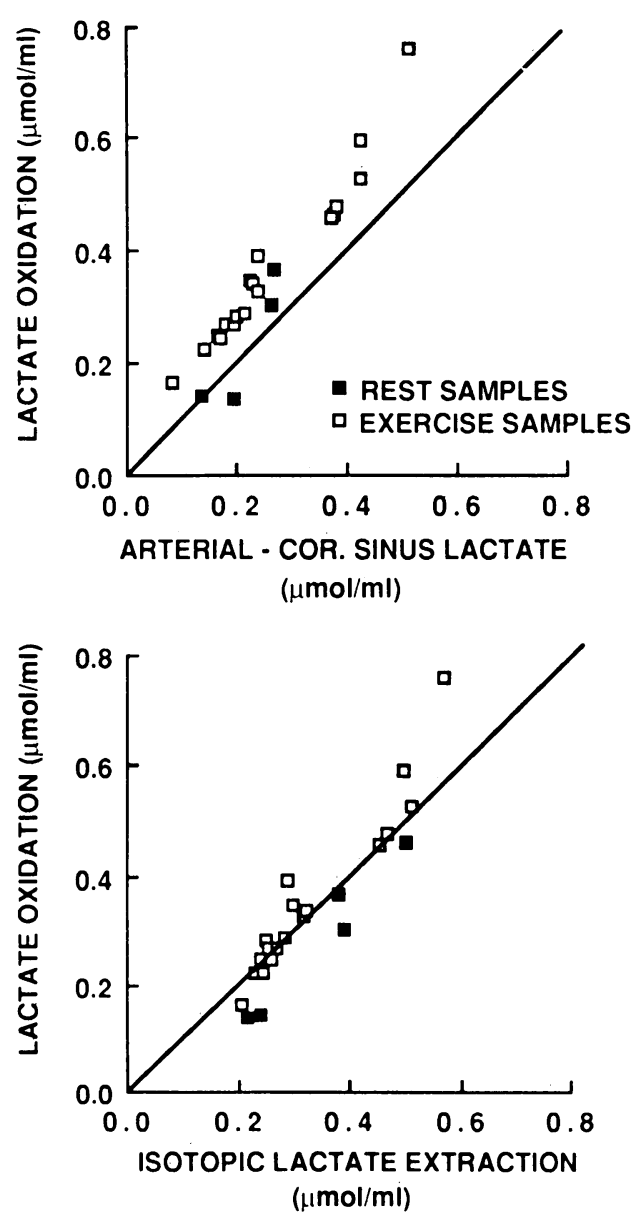

Figure 4. (Upper graph) The relationship between myocardial lactate oxidation and the chemical arterial-coronary (cor.) sinus lactate extraction for the individual data points at rest ( $\square$ ) and during moderate-intensity exercise (ㅁ). For all data points except two resting points, the amount of lactate being oxidized by the myocardium is greater than the chemical lactate extraction. The calculated mean ratio between lactate oxidized and the chemical extraction is $1.39 \pm 0.05$. This indicates that the myocardial chemical lactate extraction underestimates the amount of lactate utilized by the myocardium. (Lower graph) Myocardial lactate oxidation is compared with the isotopic lactate extraction. As shown there is a close relationship between the amount oxidized and the isotopic extraction, the ratio between the amount oxidized and the isotopic extraction is $1.00 \pm 0.04$.

Dual carbon-labeled isotopes allowed quantitation of the amount of exogenous glucose proceeding through glycolysis and being released as lactate. At rest, $0.03 \pm 0.01 \mu \mathrm{mol} / \mathrm{ml}$ or $12.3 \pm 1.5 \%$ of the glucose extracted by the myocardium was released as lactate. With coronary flow taken into account, this value is $3.4 \pm 0.8 \mu \mathrm{mol} / \mathrm{min}$, and increased to $5.7 \pm 1.4 \mu \mathrm{mol} /$ $\mathrm{min}$ at $15-20 \mathrm{~min}$ of exercise and $6.7 \pm 1.3 \mu \mathrm{mol} / \mathrm{min}$ at $25-30$ min; however, these changes were not statistically significant.

FFA Uptake. Previous reports show that the arterial-coronary sinus chemical FFA difference underestimates the myocardial extraction of this substrate $(5,15,38)$. However, FFA were not labeled in this study. Table III shows the myocardial chemical FFA extraction and uptake in these nine subjects. The mean arterial-coronary sinus chemical FFA extraction decreased during the early phase of moderate exercise; but this
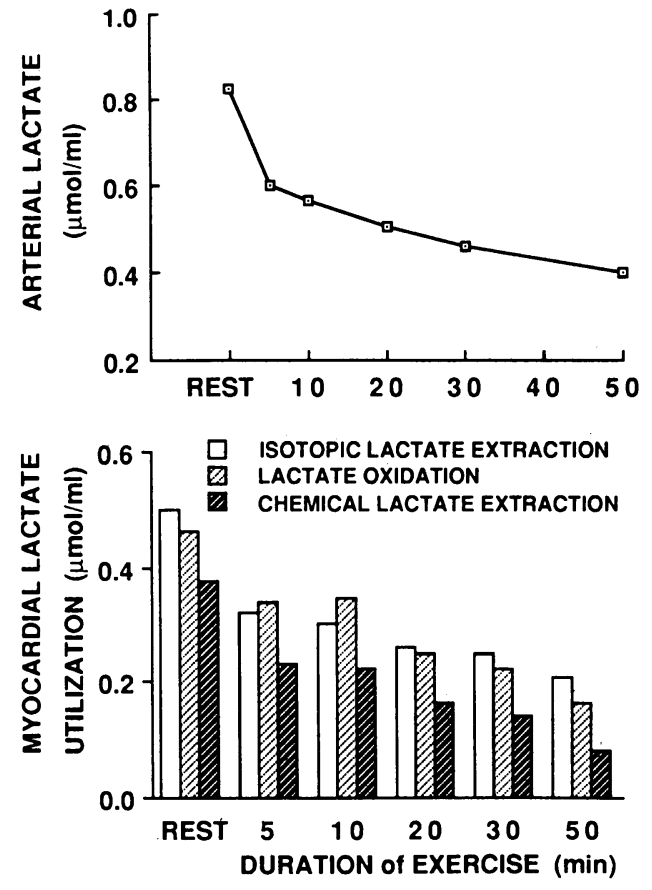

Figure 5. The arterial lactate level (upper graph) and a comparison of myocardial isotopic lactate extraction, lactate oxidation, and chemical extraction (lower graph) are shown for an individual subject (subject 8 , Table I). This individual was a well-trained cyclist, and is one of the two subjects whose lactate level fell during moderate-intensity exercise. As the circulating level fell, the isotopic lactate extraction and the amount oxidized also decreased.

difference was not significant. However, when coronary sinus blood flow is taken into account, there was a significant increase in FFA uptake during exercise $(P<0.04)$. The percent increase in chemical FFA uptake, however, was less compared with the glucose and isotopic lactate uptakes. At 15-20 min of exercise, the FFA uptake had increased to $186 \%$ of the control

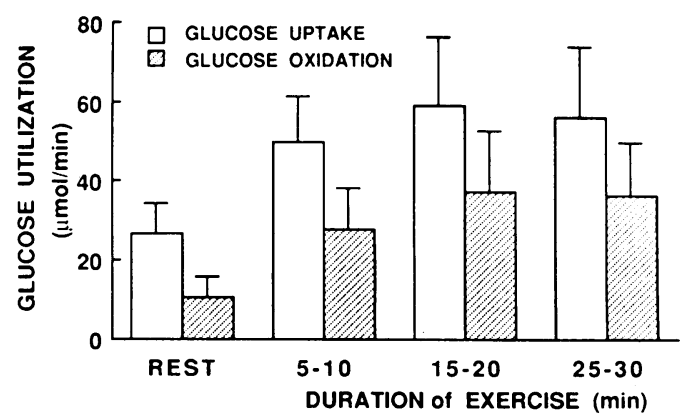

Figure 6. Comparison of myocardial glucose uptake (open bars) and the amount of exogenous glucose undergoing rapid oxidation (hatched bars) at rest and during exercise at $40 \%$ maximal $\mathrm{O}_{2}$ uptake in the six subjects receiving $\left[6-{ }^{14} \mathrm{C}\right]$ glucose. Exogenous glucose oxidation was calculated from the myocardial production of ${ }^{14} \mathrm{CO}_{2}$. The histograms represent mean $\pm \mathrm{SE}$; the data are expressed as micromoles per minute $(\mu \mathrm{mol} / \mathrm{ml} \times$ coronary sinus flow). There was a significant increase in myocardial glucose uptake with exercise $(P$ $<0.03)$. As shown, there was also a significant increase in the rate of exogenous glucose oxidation $(P<0.03)$; the percentage of extracted glucose undergoing rapid oxidation increased from $26.0 \pm 8.5 \%$ at rest to $52.6 \pm 7.3 \%$ during exercise. 
value compared with $231 \%$ for glucose uptake and $331 \%$ for isotopic lactate uptake.

Although there was an upward trend in the arterial level of FFA at 50 min of exercise, there were no significant changes in the FFA levels during exercise compared with rest. A significant positive correlation was present between the FFA chemical extraction and the arterial level at rest and during exercise $(r=0.71 ; P<0.001)$.

\section{Discussion}

In this study we have demonstrated for the first time that myocardial oxidation of exogenous glucose and lactate is increased during moderate-intensity exercise in humans. Previous human studies investigating myocardial metabolism during exercise only measured the arterial-coronary sinus differences of these substrates (14-20). In this investigation ${ }^{14} \mathrm{C}$ labeled glucose or lactate were infused as tracers and the myocardial substrate oxidation was determined by measuring the myocardial production of ${ }^{14} \mathrm{CO}_{2}$. Previously published studies have reported a decrease or no change in myocardial glucose extraction during exercise $(14-17,19)$. In the present study there were no significant changes in the arterial-coronary sinus glucose differences. However, when coronary blood flow was taken into account, a significant increase in glucose uptake was observed (Table III). Furthermore, the ${ }^{14} \mathrm{CO}_{2}$ data showed that the percentage of extracted glucose undergoing rapid oxidation also increased significantly during exercise from $26.0 \pm 8.5 \%$ at rest to $52.6 \pm 7.3 \%$ during exercise (Fig. 6). Experiments with isolated hearts have demonstrated increases in glycolysis during periods of increased myocardial work (22-24). Although the increased work in these isolated heart experiments was not associated with the hormonal and neural stimulation of moderate intensity exercise, their results and those reported in this study indicate that myocardial glucose uptake and utilization are enhanced during periods of increased workloads.

Probst et al. (39) have shown that cultured adult ventricular myocytes release lactate when incubated with room air or $100 \% \mathrm{O}_{2}$. These isolated cells were in a resting state, i.e., they were not spontaneously beating. In an anesthetized canine preparation under normoxia and nonischemic conditions, Leunissen and Piatnek-Leunissen (40) also demonstrated that the myocardium was releasing lactate despite net chemical extraction of this substrate. Recently we have demonstrated that the normal human myocardium is also releasing lactate at rest (21). These data indicate that the nonoxidative glycolytic pathway is active in the normal healthy myocardium.

Therefore, since the myocardium is simultaneously releasing and extracting this substrate, the chemical arterial-coronary sinus lactate difference, which reflects the net balance, would underestimate the true or actual amount of lactate being extracted and possibly oxidized by the myocardium. In the present study, the lactate was labeled with ${ }^{13} \mathrm{C}$ or ${ }^{14} \mathrm{C}$ in order to quantitate the true or actual extraction of this substrate. In all subjects both at rest and during exercise the myocardial chemical lactate extraction was less than the isotopic lactate extraction, indicating that the myocardium was releasing lactate.

In a subset of subjects, $\left[1-{ }^{14} \mathrm{C}\right]$ lactate was infused and the production of ${ }^{14} \mathrm{CO}_{2}$ was measured to quantitate the amount of lactate being oxidized by the myocardium during moderate-intensity exercise. Under these conditions we found that $100.4 \pm 3.5 \%$ of the isotopic lactate extracted undergoes rapid oxidation. If the amount oxidized as calculated by the ${ }^{14} \mathrm{CO}_{2}$ production is compared with the chemical uptake, the theoretical percentage would be $139.4 \pm 4.6$. Thus the ${ }^{14} \mathrm{CO}_{2}$ measurement, independent of the isotopic uptake, demonstrates that the chemical lactate extraction underestimates myocardial oxidation of this substrate. Both our isotopic lactate and ${ }^{14} \mathrm{CO}_{2}$ findings indicate that previous studies measuring only the chemical lactate difference underestimated the myocardial uptake and utilization of this important substrate. In this study, we observed a close correlation between lactate oxidation and the arterial lactate level. As shown in Fig. 5, we found a decrease in myocardial lactate oxidation as the arterial lactate level declined with prolonged exercise.

In contrast to the data on lactate which shows $100 \%$ oxidation, we found that only $26.0 \pm 8.5 \%$ of the glucose extracted is undergoing rapid oxidation at rest. Another $12.3 \pm 1.5 \%$ of the extracted glucose proceeded through glycolysis and was released as lactate. Thus $60 \%$ of the exogenous glucose extracted by the myocardium at rest enters a slow turnover pool, presumably glycogen. This is a limitation of our isotopic technique in that we are not able to measure the specific activity of glucose-6-phosphate or other metabolic intermediates in the glycolytic pathway. Prolonged isotope infusion will result in enhanced labeling in this storage pool which could result in changes in the specific activity of these glycolytic intermediates. The duration of the isotope infusions in this study was $96 \pm 5 \mathrm{~min}$. In previous experiments, we have measured myocardial exogenous glucose oxidation over a $98 \pm 3$-min period in resting subjects and have found no increase in exogenous glucose oxidation values during this time period (21). Thus, we believe that the increase in exogenous glucose oxidation observed in this study is related to the increase in myocardial work and not to prolonged isotope infusion.

Another limitation of the technique is that we are not able to measure total glycolysis, i.e., the contribution of glycogen to glycolysis and amount of glycogen being oxidized. The difference between the total lactate release and the lactate coming from exogenous glucose presumably represents the contribution of glycogen to nonoxidative glycolysis. This same relative ratio of exogenous glucose to endogenous glucose (glycogen) is probably entering glycolysis and being oxidized. The results in this study dealing with glucose metabolism all refer to the metabolic fate of exogenous glucose and not glycogen. Animal studies measuring glycogen levels have shown that myocardial glycogen decreases with moderate to heavy intensity exercise $(41,42)$. Thus, metabolism of both exogenous glucose and endogenous stores is increased during exercise.

To determine the contribution of a substrate to oxidative metabolism, an oxygen extraction ratio is often calculated. In previous studies oxygen extraction ratios have been calculated for glucose and lactate from the arterial-coronary sinus chemical differences $(5-7,14-18,20)$. In this study the oxygen equivalents can be calculated from the amount of each substrate oxidized based on the ${ }^{14} \mathrm{CO}_{2}$ data. If these oxygen equivalents are calculated on the six subjects receiving $\left[6-{ }^{14} \mathrm{C}\right]-$ glucose and $\left[\mathrm{U}-{ }^{13} \mathrm{C}\right]$ lactate, one finds that the contribution of exogenous glucose to oxidative metabolism increased significantly from $8.6 \pm 3.3 \%$ at rest to $13.6 \pm 3.5 \%$ during the early phase of moderate exercise (first $15 \mathrm{~min}$ of exercise) $(P<0.01)$. 
These values only pertain to the contribution of exogenous glucose to oxidative metabolism. The contribution of lactate to oxidative metabolism also significantly increased from $13.6 \pm 2.0 \%$ at rest to $27.6 \pm 6.1 \%$ during moderate exercise $(P$ $<0.025)$. These percentages are based on the isotopic lactate extraction values.

The effect of moderate intensity exercise on circulating substrate levels has been well characterized (9-13, 17, 43-50). Several investigators have measured lactate and FFA concentrations and turnover rates during exercise $(12,13,44,46,47$, $49,50)$. In 1936 Bang reported that during prolonged moderate-intensity exercise, an early rise in systemic lactate occurred (9). This early elevation in lactate level peaked within 5-10 min of exercise; after this early peak the lactate level fell slowly with continuous exercise at the same workload. Seven of the nine subjects in the present study had an early rise in circulating lactate which peaked at $5 \mathrm{~min}$. The arterial lactate in the remaining two subjects (subjects 8 and 9, Table $\mathrm{I}$ ) fell during the entire 50-min exercise period. Both subjects (subjects 8 and 9) were highly trained, competitive cyclists. Several investigators have measured the systemic lactate response to exercise in trained and sedentary subjects $(10,17,18,43)$. They reported that with physical training the rise in arterial lactate to similar strenuous workloads is diminished. All subjects in this investigation were active in physical training, however as shown in Table I the type and degree of physical training varied and we believe this factor accounts for the wide range in the circulating lactate levels observed in our study. During very strenuous exercise, exponential rises in lactate have been reported (11, 13). We observed similar rises in arterial lactate in the three subjects exercising at $80 \%$ maximal $\mathrm{O}_{2}$ uptake. However, exponential rises in circulating lactate were not seen in any of the subjects exercising at the moderate workload of $40 \%$ maximal $\mathrm{O}_{2}$ uptake.

There were no significant changes in the arterial glucose levels during the $50 \mathrm{~min}$ of exercise at $40 \%$ of maximal $\mathrm{O}_{2}$ uptake; this is similar to the findings reported by other investigators $(10,47)$. However, despite no changes in the circulating glucose, there was a significant increase in myocardial glucose uptake and exogenous glucose oxidation with exercise. During exercise, not only are there alterations in the circulating substrates but also hormonal levels and sympathetic activity are also changing. These levels were not measured in the present investigation. Wahlqvist et al. (15) and Ahlborg et al. $(44,45)$ observed significant decreases in insulin levels with prolonged exercise. In addition, Wahlqvist et al. (15) measured growth hormone and glucocorticoid levels and found no significant changes in these levels with exercise. Ahlborg et al. $(44,45)$ reported significant increases in both epinephrine and norepinephrine levels during exercise. The enhanced myocardial glucose uptake and exogenous glucose oxidation which were observed in this study may in part be related to the catecholamine changes associated with exercise.

In summary, we have demonstrated for the first time that the myocardial oxidation of exogenous glucose and lactate increases during moderate-intensity exercise in trained human subjects. Myocardial glucose uptake $(\mu \mathrm{mol} / \mathrm{ml} \times$ flow $)$ increased in all subjects during exercise. The percentage of glucose extracted by the myocardium undergoing rapid oxidation also significantly increased during exercise. With the early rise of circulating lactate during exercise, there was a significant increase in myocardial lactate uptake. We also showed that the traditional arterial-coronary sinus chemical lactate extraction underestimates the amount of lactate extracted and oxidized by the myocardium both at rest and during exercise.

\section{Acknowledgments}

We express our appreciation to Maria Mayr and Chit S. Kwan for their assistance with the biochemical analyses, and to Mary Parks for her technical assistance in the cardiac catheterization laboratory.

This study was supported in part by the Medical Research Service of the Veterans Administration, San Francisco, California and by grant HL-25625 from the National Institutes of Health. Dr. Stanley was the recipient of a postdoctoral fellowship from the California Affiliate of the American Heart Association, with funding provided by the Orange County and San Francisco Chapters.

\section{References}

1. Opie, L. H. 1968. Metabolism of the heart in health and disease. Part 1. Am. Heart J. 76:685-698.

2. Neely, J. R., M. J. Rovetto, and J. F. Oram. 1972. Myocardial utilization of carbohydrate and lipids. Prog. Cardiovasc. Dis. 15:289329.

3. Liedtke, A. J. 1981. Alterations of carbohydrate and lipid metabolism in the acutely ischemic heart. Prog. Cardiovasc. Dis. 23:321336.

4. Shipp, J. C., L. H. Opie, and D. Challoner. 1961. Fatty acid and glucose metabolism in the perfused heart. Nature (Lond.). 189:10181019.

5. Lassers, B. W., L. Kaijser, and L. A. Carlson. 1972. Myocardial lipid and carbohydrate metabolism in healthy, fasting men at rest: studied during continuous infusion of ${ }^{3} \mathrm{H}$-palmitate. Eur. J. Clin. Invest. 2:348-358.

6. Bing, R. J., A. Siegel, A. Vitale, F. Balboni, E. Sparks, M. Taeschler, M. Klapper, and S. Edwards. 1953. Metabolic studies on the human heart in vivo. I. Studies on carbohydrate metabolism of the human heart. Am. J. Med. 15:284-296.

7. Scott, J. C., L. J. Finkelstein, and J. J. Spitzer. 1962. Myocardial removal of free fatty acids under normal and pathological conditions. Am. J. Physiol. 203:482-486.

8. Gertz, E. W., J. A. Wisneski, R. Neese, A. Houser, R. Korte, and J. D. Bristow. 1980. Myocardial lactate extraction: multi-determined metabolic function. Circulation. 61:256-261.

9. Bang, O. 1936. The lactate content of the blood during and after muscular exercise in man. Skand. Arch. Physiol. 74(Suppl. 10):49-82.

10. Cobb, L. A., and W. P. Johnson. 1963. Hemodynamic relationships of anaerobic metabolism and plasma free fatty acids during prolonged, strenuous exercise in trained and untrained subjects. $J$. Clin. Invest. 42:800-810.

11. Keppler, D., J. Keul, and E. Doll. 1969. The influence of the form of exercise on the arterial concentrations of glucose, lactate, pyruvate, and free fatty acids. In Biochemistry of Exercise. Medicine and Sport. J. R. Poortmans, editor. S. Karger, Basel, New York. 132-136.

12. Eldridge, F. L. 1975. Relationship between turnover rate and blood concentration of lactate in exercising dogs. J. Appl. Physiol. 39:231-234.

13. Stanley, W. C., E. W. Gertz, J. A. Wisneski, D. L. Morris, R. A. Neese, and G. A. Brooks. 1985. Systemic lactate kinetics during graded exercise in man. Am. J. Physiol. 249 (Endocrinol. Metab. 12):E595E602.

14. Kaijser, L., B. W. Lassers, M. L. Wahlqvist, and L. A. Carlson. 1972. Myocardial lipid and carbohydrate metabolism in fasting men during prolonged exercise. J. Appl. Physiol. 32(6):847-858.

15. Wahlqvist, M. L., L. Kaijser, B. W. Lassers, H. Low, and L. A. Carlson. 1973. The role of fatty acid and of hormones in the determination of myocardial carbohydrate metabolism in healthy fasting men. Eur. J. Clin. Invest. 3:57-65. 
16. Lassers, B. W., L. Kaijser, M. L. Wahlqvist, and L. A. Carlson. 1971. Myocardial metabolism in man at rest and during prolonged exercise. Adv. Exp. Med. Biol. 11:457-467.

17. Keul, J. 1971. Myocardial metabolism in athletes. $A d v$. Exp. Med. Biol. 11:447-455.

18. Heiss, H. W., J. Barmeyer, K. Wink, G. Hell, F. J. Cerny, J. Keul, and H. Reindell. 1976. Studies on the regulation of myocardial blood flow in man. I. Training effects on blood flow and metabolism of the healthy heart at rest and during standardized heavy exercise. Basic Res. Cardiol. 71:658-675.

19. Carlsten, A., B. Hallgren, R. Jagenburg, A. Svanborg, and L. Werko. 1961. Myocardial metabolism of glucose, lactic acid, amino acids and fatty acids in healthy human individuals at rest and at different work loads. Scand. J. Clin. Lab. Invest. 13:418-428.

20. Bertrand, M. E., A. G. Carre, A. P. Ginestet, J. M. Lefebvre, L. A. Desplanque, and J. P. Lekieffre. 1977. Maximal exercise in normal subjects: changes in coronary sinus blood flow, contractility and myocardial extraction of FFA and lactate. Eur. J. Cardiol. 56:481-491.

21. Wisneski, J. A., E. W. Gertz, R. A. Neese, L. D. Gruenke, D. L. Morris, and J. C. Craig. 1985. Metabolic fate of extracted glucose in normal human myocardium. J. Clin. Invest. 76:1819-1827.

22. Opie, L. H., K. R. L. Mansford, and P. Owen. 1971. Effects of increased heart work on glycolysis and adenine nucleotides in the perfused heart of normal and diabetic rats. Biochem. J. 124:475-490.

23. Achs, M. J., D. Garfinkel, and L. H. Opie. 1982. Computer simulation of metabolism of glucose-perfused rat heart in a workjump. Am. J. Physiol. 243 (Regulatory Integrative Comp. Physiol. 12):R389-R399.

24. Marshall, R. C., W. W. Nash, K. I. Shine, M. E. Phelps, and N. Ricchiuti. 1981. Glucose metabolism during ischemia due to excessive oxygen demand or altered coronary flow in the isolated arterially perfused rabbit septum. Circ. Res. 49:640-648.

25. Bruce, R. A., and T. R. Hornsten. 1969. Exercise stress testing in evaluation of patients with ischemic heart disease. Prog. Cardiovasc. Dis. 11:371-390.

26. Sheffield, L. T., and D. Roitman. 1976. Stress testing methodology. Prog. Cardiovasc. Dis. 19:33-49.

27. Hughes, E. F., S. C. Turner, and G. A. Brooks. 1982. Effects of glycogen depletion and pedaling speed on "anaerobic threshold." $J$. Appl. Physiol. 52:1598-1607.

28. Gertz, E. W., J. A. Wisneski, R. Neese, J. D. Bristow, G. L. Searle, and J. T. Hanlon. 1981. Myocardial lactate metabolism: evidence of lactate release during net chemical extraction in man. Circulation. 63:1273-1279.

29. Ganz, W., K. Tamura, H. S. Marcus, R. Donoso, S. Yoshida, and H. J. C. Swan. 1971. Measurement of coronary sinus blood flow by continuous thermodilution in man. Circulation. 44:181-195.

30. Bier, D. M., R. D. Leake, M. W. Haymond, K. J. Arnold, L. D. Gruenke, M. A. Sperling, and D. M. Kipnis. 1977. Measurement of "true" glucose production rates in infancy and childhood with 6,6-dideuteroglucose. Diabetes. 26:1016-1023.

31. Wiecko, J., and W. R. Sherman. 1976. Boroacetylation of carbohydrate. Correlations between structure and mass spectral behavior in monoacetylhexose cyclic boronic esters. J. Am. Chem. Soc. 98:7631-7637.
32. Van Slyke, D. D., and J. M. Neill. 1924. Determination of gases in blood and other solutions by vacuum extraction and manometric measurement. J. Biol. Chem. 61:523-573.

33. Choi, S. C. 1978. Introductory Applied Statistics in Science. Prentice-Hall, Inc., Englewood Cliffs, NJ. 146-148.

34. Miller, R. 1981. Simultaneous Statistical Inference. SpringerVerlag, New York. 67-70.

35. Zar, J. H. 1974. Biostatistical Analysis. Prentice-Hall, Inc., Englewood Cliffs, NJ. 198-225.

36. Stenberg, J., P. O. Åstrand, B. Ekblom, J. Royce, and B. Saltin. 1967. Hemodynamic response to work with different muscle groups, sitting and supine. J. Appl. Physiol. 22:61-70.

37. Åstrand, P. O., and K. Rodahl. 1977. Textbook of Work Physiology: Physiological Bases of Exercise. McGraw-Hill Book Co., New York. 391-438.

38. Wisneski, J. A., E. W. Gertz, R. A. Neese, and M. Mayr. 1987. Myocardial metabolism of free fatty acids. Studies with 14C-labeled substrates in humans. J. Clin. Invest. 79:359-366.

39. Probst, I., R. Spahr, C. Schweickhardt, D. H. Hunneman, and H. M. Piper. 1986. Carbohydrate and fatty acid metabolism of cultured adult cardiac myocytes. Am. J. Physiol. 250 (Heart Circ. Physiol. 19):H853-H860.

40. Leunissen, R. L. A., and D. A. Piatnek-Leunnissen. 1973. Myocardial lactate oxidation and release in the dog in vivo. Pfluegers Arch. Eur. J. Physiol. 344:261-270.

41. Judd, W. T., and J. L. Poland. 1972. Myocardial glycogen changes with exercise. Proc. Soc. Exp. Biol. Med. 140:955-957.

42. Goldfarb, A. H., J. F. Bruno, and P. J. Buckenmeyer. 1986. Intensity and duration effects of exercise on heart cAMP, phosphorylase, and glycogen. J. Appl. Physiol. 60:1268-1273.

43. Crescitelli, F., and C. Taylor. 1944. The lactate response to exercise and its relationship to physical fitness. Am. J. Physiol. 141:630-640.

44. Ahlborg, G., P. Felig, L. Hagenfeldt, R. Hendler, and J. Wahren. 1974. Substrate turnover during prolonged exercise in man. Splanchnic and leg metabolism of glucose, free fatty acids, and amino acids. J. Clin. Invest. 53:1080-1090.

45. Ahlborg, G., and P. Felig. 1982. Lactate and glucose exchange across the forearm, legs, and splanchnic bed during and after prolonged leg exercise. J. Clin. Invest. 69:45-54.

46. Friedberg, S. J., W. R. Harlan, Jr., D. L. Trout, and E. H. Esters, Jr. 1960. The effect of exercise on the concentration and turnover of plasma nonesterified fatty acids. J. Clin. Invest. 39:215-220.

47. Havel, R. J., A. Naimark, and C. F. Borchgrevink. 1963. Turnover rate and oxidation of free fatty acids of blood plasma in man during exercise: studies during continuous infusion of palmitate-1- $\mathrm{C}^{14}$. J. Clin. Invest. 42:1054-1063.

48. Young, D. R., R. Pelligra, and R. R. Adachi. 1966. Serum glucose and free fatty acids in man during prolonged exercise. J. Appl. Physiol. 21:1047-1052.

49. Miller, H., B. Issekutz, Jr., and K. Rodahl. 1963. Effect of exercise on the metabolism of fatty acids in the dog. Am. J. Physiol. 205:167-172.

50. Miller, H. I., K. Y. Yum, and B. C. Durham. 1971. Myocardial free fatty acid in unanesthetized dogs at rest and during exercise. Am. J. Physiol. 220:589-596. 